\title{
Self-Potential Anomalies Associated with an Active Fault
}

\author{
Hideki MURAKami*†, Hitoshi MizUTANi*, and Sachio NABETANI** \\ *Department of Earth Sciences, School of Science, Nagoya University, Nagoya, \\ Japan \\ **Department of Earth Sciences, Faculty of Science, Hirosaki University, Hirosaki, \\ Japan
}

(Received December 6, 1983; Revised April 23, 1984)

In order to investigate fault activity, a self-potential survey was made near the surface faults of the 1896 Rikuu earthquake $(M=7.2)$ in the Tohoku district of Japan. These surface faults are reverse and dip east. The following characteristic changes of the self-potential were observed; (1) the self-potentials at the east side of the fault were about 20 to $50 \mathrm{mV}$ larger than those at the west side, (2) the positions of the step of the self-potential profiles across the fault deviate more east from the surface fault trace as the survey line goes down to the south. These anomalies are successfully explained by the electrokinetic processes due to the fluid flowing out from the fault using the observed geoelectric structure of the fault. It requires that the fluid pressure (above hydrostatic) at the fault is a few bars higher than that around it. The electrokinetic current, however, produces only $0.2 \mathrm{nT}$ on the surface, whereas the observed geomagnetic anomaly amounts to over $100 \mathrm{nT}$ above the fault. The large magnetic anomaly should have a different origin from that of the self-potential anomaly.

\section{Introduction}

For an earthquake prediction study, it is important to make clear the physical properties of an active fault using various kinds of geophysical and geological methods. Geomagnetic and geoelectric studies on earthquake prediction have recently become a subject of special interest. The self-potential, resistivity, and geomagnetic variations preceding earthquakes have been reported (for example, CORWIN and MORRISON, 1977; YAMAZAKI, 1977; and SMITH and JOHNSON, 1976). Electromagnetic Research Group for the Active Fault (1982) reports the electromagnetic survey results at Yamasaki fault in Hyogo Prefecture, Japan. It is revealed that there is a zone along the fault in which the electrical resistivity is low, ranging 100 to $300 \mathrm{ohm}$-meter, whereas a resistivity of the order of 1000 ohm-meter is observed outside the fractured zone. Within this low resistivity zone, there are belts of extremely low resistivity of 10 to $30 \mathrm{ohm}$-meter. The locations of these belts correspond to the fault plane in the surface inferred from geological inspection. But geoelectric and geomagnetic data on active faults are insufficient,

†Now at Department of Geology, Faculty of Science, Kochi University, Kochi, Japan. 
and there still remains a wide unexplored domain. In this study we report a part of the results obtained in the project study on the fault activity using geoelectric and geomagnetic methods which were organized by NoRITOMI (1981).

We measured the self-potentials at the faults in Akita Prefecture, Japan, which occurred in association with the Rikuu earthquake $(M=7.2)$ of 1896 . This is the largest land-surface fault of the thrust type among those associated with historical earthquakes in Japan. Four main surface ruptures on the western foot of the Mahiru Mountains constitute the main fault zone of the 1896 earthquake (MATSUDA et al., 1890). In this area stray currents are very small because this area is located a great distance from any industrial area, power lines, and the railroad. It is thus believed that the present self-potential survey results are free from artifical noise and constitutes some of the most reliable data of that which we have obtained. In this paper we describe the self-potential distribution across the surface faults and propose an electrokinetic model for the self-potential anomalies associated with the faults.

\section{Field Procedure}

The measurements of the self-potential were made along six lines, which traversed perpendicular to the surface faults, in order to study the distribution of the self-potential across the fault. Figure 1 shows locations of the survey lines.

The basic equipment for measuring the self-potential consisted of a pair of copper-copper sulfate nonpolarizing electrodes and a digital voltmeter or a potentiometer. A stable reading was usually obtained within a few minutes after the electrodes contact with the ground. The electrode polarization, which was checked by the simple method of setting a pair of electrodes in a side-by-side arrangement, was usually less than $3 \mathrm{mV}$. The results of the measurement were corrected when electrode polarization existed. A "gradient" or "leapfrog" survey configuration (in which a dipole of fixed length was stepped along the survey line, and successive voltages added to obtain the total field) and a "total field" survey configuration (in which a fixed base electrode was used for the entire survey) were used. When a "gradient" survey configuration was used, electrodes were spaced $25 \mathrm{~m}$ or $50 \mathrm{~m}$ apart depending upon the circumstances. It seems that the accuracy of the measurement was $\pm 2 \mathrm{mV}$ over electrode spacing 50 $\mathrm{m}$. The differences of readings in the reverse survey along the same line were generally smaller than $2 \mathrm{mV}$. There were cases in which the local distribution of the self-potential was so complicated that the differences of measurements only a few meters apart were more than $5 \mathrm{mV}$. In these cases, we only report average values of several points randomly sampled in an area of around $10 \mathrm{~m} \times 10$ m.

CORWIN and Hoover (1979) discussed some problems on the self-potential method. Survey procedures, such as stepwise advancement of a short measuring dipole ("leapfrog" technique) or the watering of electrodes to improve ground contact, lead to serious cumulative errors when used over long survey lines. The 


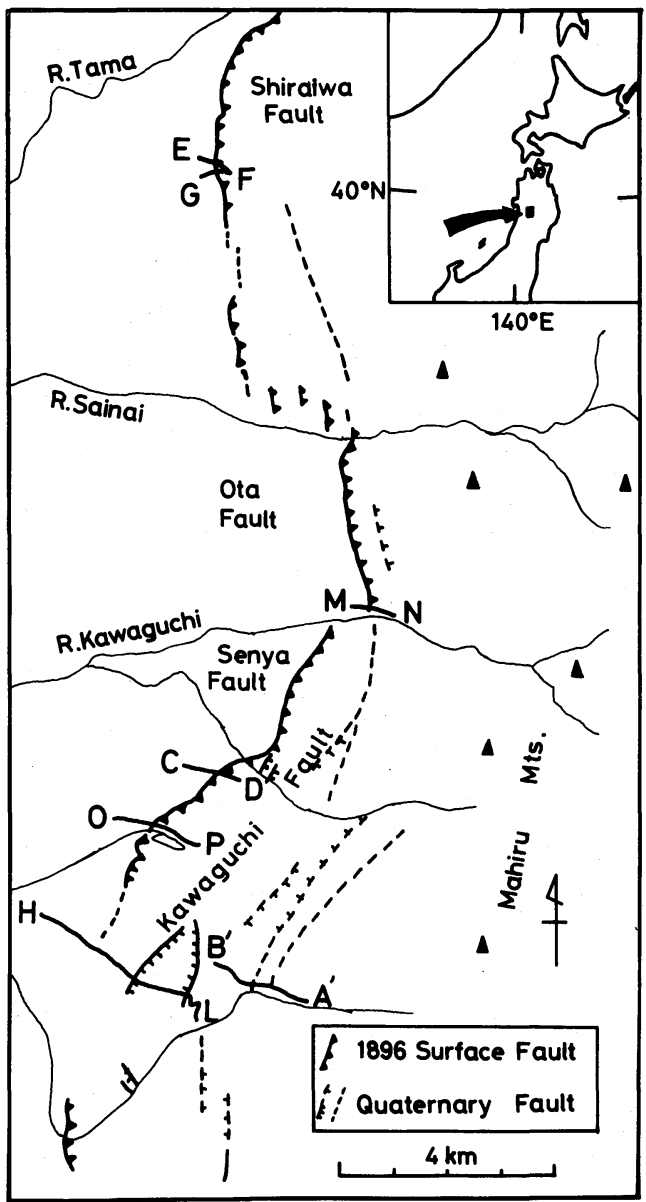

Fig. 1. Index map showing the survey lines and the surface faults associated with the 1896 Rikuu earthquake on the western foot of the Mahiru Mountains. Survey lines; E-F-G, M-N, C-D, O-P, H-L, and B'-A'. 1896 surface faults; Shiraiwa fault, Ota fault, and Senya fault (after MATSUDA et al., 1980).

"leapfrog" survey is subject to positive cumulative errors in the traverse direction, caused by the fresher watering of the leading electrode. We reversed the relative position of the electrodes for alternate readings in order to minimize cumulative errors caused by electrode polarization when we used a "leapfrog" survey configuration. Since the survey area had been rained on and the soil was already saturated, we considered that the effect of watering electrodes was very small. 


\section{Survey Results}

Figures 2 to 9 show the data obtained along the survey lines given in Fig. 1, and the locations of the surface faults described by MATSUDA et al. (1980) are also indicated by shaded bars.

\subsection{Line $E-F-G$}

This survey line traverses Shiraiwa fault in a paddy field, and consists of the line E-F and the line F-G (see Fig. 1). The topographic effect on the selfpotential is negligible because the difference of the height along the survey line is smaller than $10 \mathrm{~m}$. A "gradient" survey configuration was used and individual readings were added successively in order to construct the total field self-potential relative to the base point E. Figure 2 shows the self-potential profiles in the two forms of measured (gradient), calculated (total field) values along the line $\mathrm{E}-\mathrm{F}$ and the line F-G. It is evident that the gradient of the self-potential in the vicinity of the fault is large as shown in the bottom of Fig. 2. The fault exists at the boundary between the east side high and the west low (total) selfpotentials, and the difference across the fault is about $20 \mathrm{mV}$.

\subsection{Line $M-N$}

As shown in Fig. 1, this survey line also traverses the surface fault line (Ota fault). Figure 3 shows the total field self-potential profile obtained along the line M-N, using a "total field" survey configuration. Reading intervals were $20 \mathrm{~m}$. Although the distribution of the self-potential in the vicinity of the fault

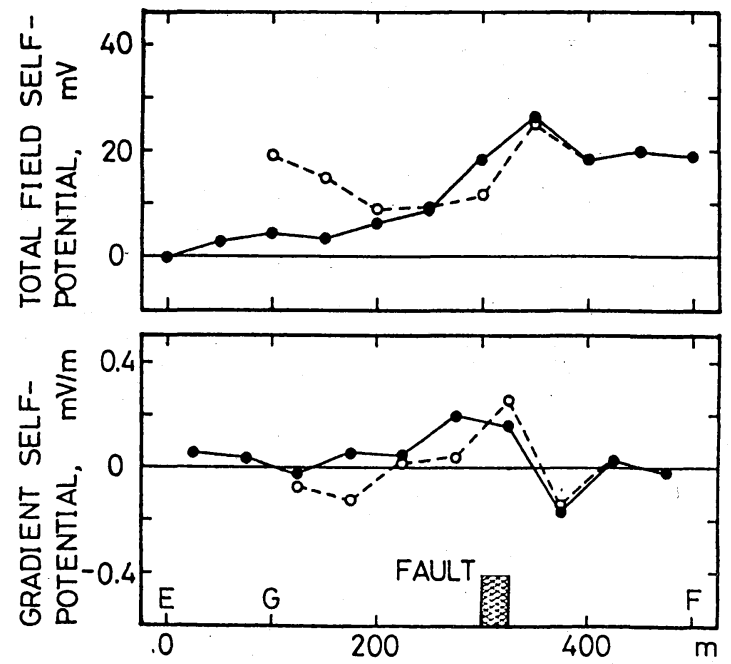

Fig. 2. Gradient and total field self-potential profile across. Shiraiwa fault, line E-F-G. The solid line represents the profile along line E-F, and the broked line represents the profile along line F-G. 


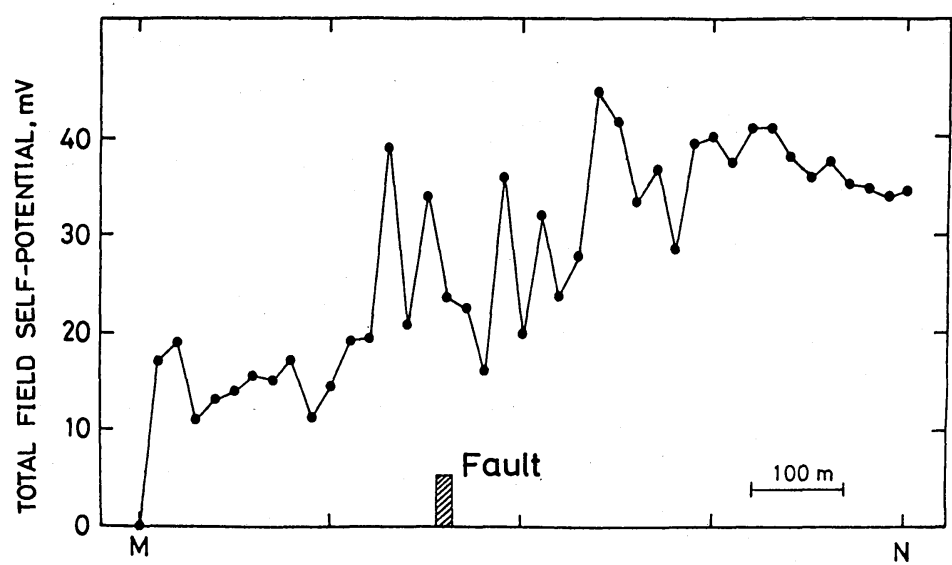

Fig. 3. Total field self-potential profile across Ota fault, line $\mathbf{M}-\mathbf{N}$.

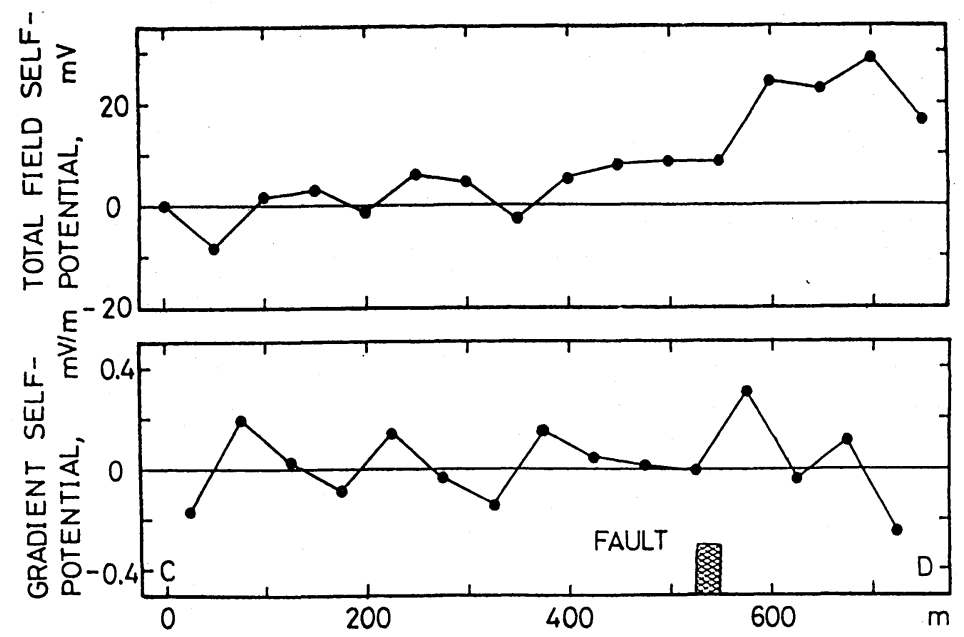

Fig. 4. Gradient and total field self-potential profile across Senya fault, line C-D.

is rather jagged, the self-potential on the east side of the fault is about $20 \mathrm{mV}$ larger than that on the west side. The total intensity of the geomagnetic field was also measured along this survey line and a geomagnetic anomally larger than $100 \mathrm{nT}$ was observed near the fault (Mishina and YAMASHITA, 1981). The coincidence between the self-potential anomalies and the geomagnetic anomalies seems to suggest some causal relation between the two.

\subsection{Line $C-D$}

This survey line traverses Senya fault. The measurement was made by a "gradient" survey configuration with electrodes spaced $50 \mathrm{~m}$ apart. Figure 4 shows both the gradient and total field of the self-potential. As shown in the 
bottom of Fig. 4, the self-potential gradient profile does not seem to be affected by the existence of the fault, but the total field profile shows that the self-potential on the east side of the fault is larger about $20 \mathrm{mV}$ than that on the west side. The overall trend of the total field profile is similar to that obtained along the line $\mathrm{E}-\mathrm{F}-\mathrm{G}$ and $\mathrm{M}-\mathrm{N}$.

\subsection{Line $O-Q-P$}

Figure 5 shows the location of the survey line O-Q-P. This survey line also traverses Senya fault. The measurement was made by a "total field" survey configuration. Figure 6 shows the profile of the total field self-potential relative to the base point $\mathrm{Q}$ between point $\mathrm{O}$ and $\mathrm{P}$. It is remarkable that the self-potentials step up at the point $100 \mathrm{~m}$ east of the surface fault line, which is shaded in Fig. 6. This self-potential high area coincides with the area where the geomagnetic anomaly of about $250 \mathrm{nT}$ (see Fig. 15) was reported by MiSHINA and YAMASHITA (1981). But geophysical significances of the positive anomaly of about $50 \mathrm{mV}$, $140 \mathrm{~m}$ east of point $\mathrm{O}$, and negative anomalies of 30 to $50 \mathrm{mV}, 350 \mathrm{~m}$ west of point $\mathrm{Q}$, are not evident at present. Neglecting these local anomalies, the self-potentials on the east side of the fault are about $30 \mathrm{mV}$ larger than those on the west side.

\subsection{Line $H-I-J-K^{\prime}-K-L$}

As shown in Fig. 5, the survey line is located $1 \mathrm{~km}$ south of the southern end of the surface fault line, and traverses across the elongation of it. This survey line traverses two Quaternary faults between point I and J, and between point $\mathrm{K}$ ' and $\mathrm{K}$. The survey was made by a "gradient"' survey configuration with electrodes spaced $50 \mathrm{~m}$ apart, and $25 \mathrm{~m}$ apart only between point I and J. Figure

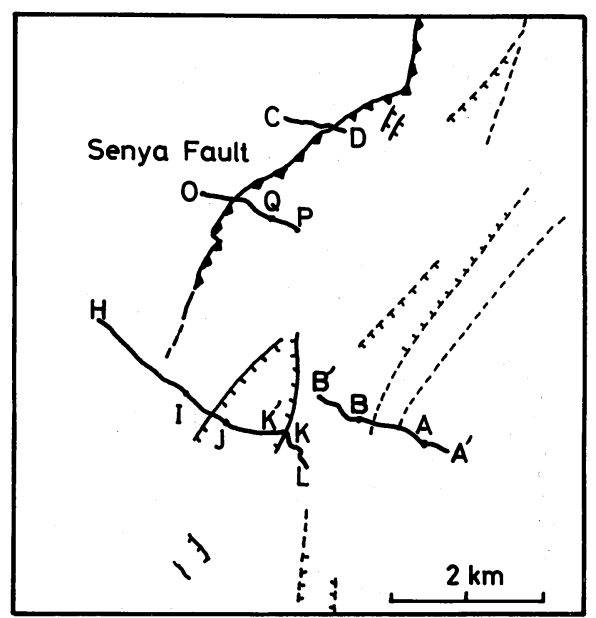

Fig. 5. Locations of survey line C-D, line $\mathrm{O}-\mathrm{Q}-\mathrm{P}$, line $\mathrm{H}-\mathrm{I}-\mathrm{J}-\mathrm{K}$ '-K-L, line $\mathrm{B}^{\prime}-\mathrm{B}-\mathrm{A}-\mathrm{A}^{\prime}$, and surface fault traces. 


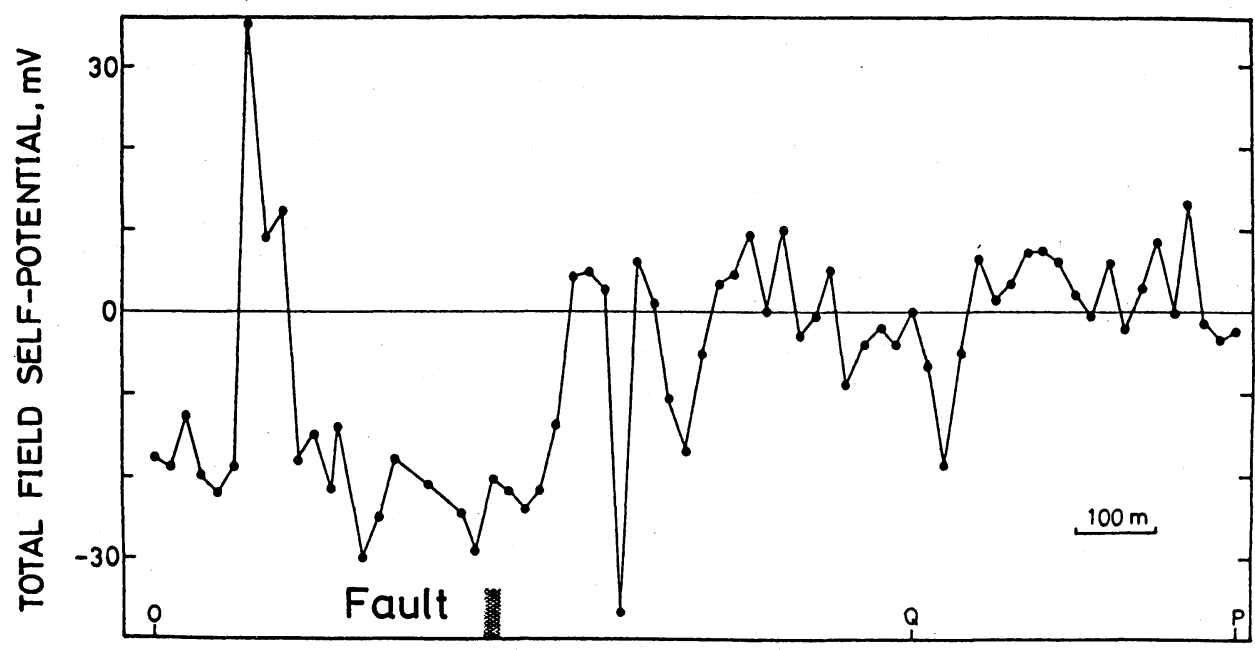

Fig. 6. Total field self-potential profile across Senya fault, line O-Q-P.

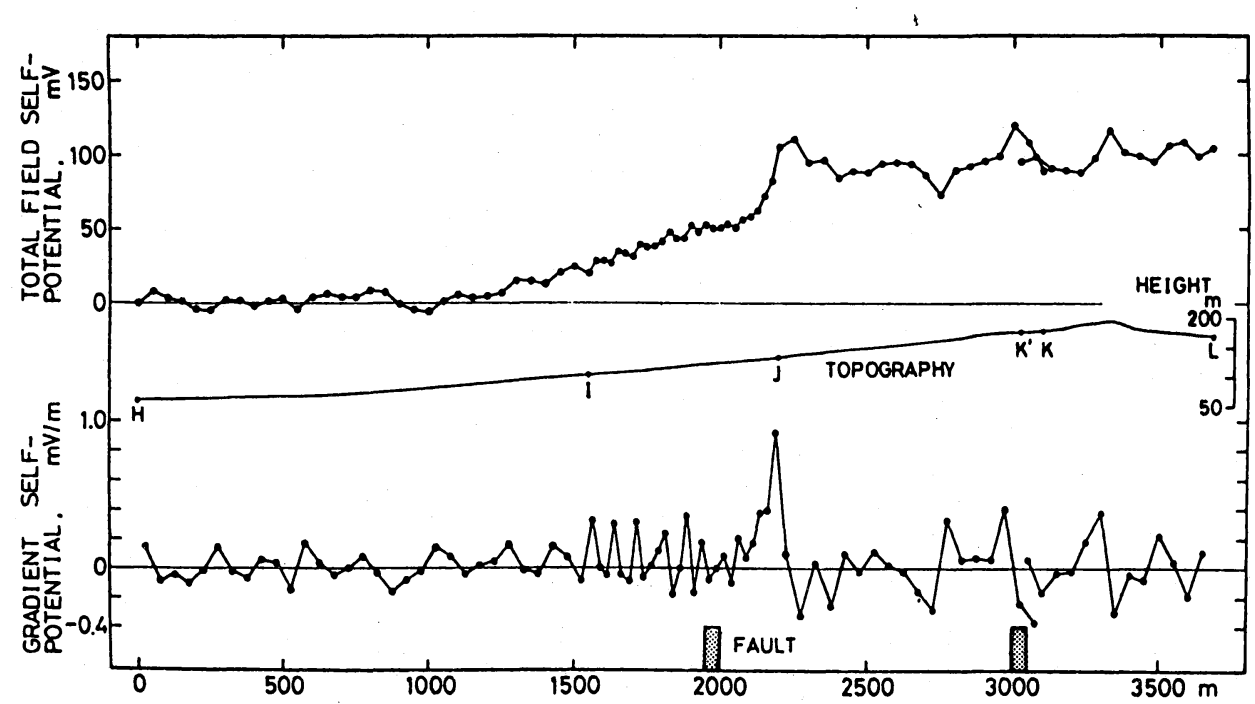

Fig. 7. Gradient, total field self-potential, and topographic profile along the survey line H-I-JK'-K-L. This survey line traverses two Quaternary faults(shaded bar) and the elongation of Senya fault, about $1 \mathrm{~km}$ east of the base point $\mathrm{H}$. Quaternary faults are thought to be the elongation of Ota fault (MATSUDA et al., 1980).

7 shows the gradient and the total field self-potential relative to base point $\mathrm{H}$. As shown in Fig. 7, the self-potential increases suddenly toward the east near point J. Point $J$ is located near the Quaternary fault, which is thought to be the elongation of the Ota fault but was inactive during the 1896 earthquake 
(MATsuda et al., 1980). The self-potential on the east side of this fault is about 40 to $50 \mathrm{mV}$ larger than that on the west side. But self-potential anomalies were not observed at the other Quaternary faults and the elongation of the Senya fault. The measurements of the gradient of the self-potential along the survey line and perpendicular to it were also made between point $\mathrm{I}$ and $\mathrm{J}$, and the vectors of the self-potential gradient at every point between point $\mathrm{I}$ and $\mathrm{J}$ were calculated from the data. Figure 8 shows the direction and the magnitude of the vector of the self-potential gradient at every point. It is remarkable that the direction of the vector varies gradually from point $I$ to point $J$, and the direction of the vectors near point $J$ is perpendicular to the fault line. The vectors of the self-potential gradient may have important implications on the cause of the self-potential anomalies associated with this fault. In the next section we propose the interpretation on the vectors of the self-potential gradient.

\subsection{Line $B^{\prime}-B-A-A^{\prime}$}

As shown in Fig. 5, this survey line traverses two faults, which are thought to be less-active Quaternary faults (MATSUDA et al., 1981). The survey was made by a "gradient" survey configuration with electrodes spaced $50 \mathrm{~m}$ apart. The survey result is shown in Fig. 9. In some places we observed large gradients of the self-potentials and positive peaks of the total self-potentials. However, the correlation between these self-potential anomalies and faults are not evident. The distribution of the self-potential obtained along this survey line is different from those associated with active faults. The poor correlations of the self-potentials and the faults may, be related to the low activity of the faults in this region.

\section{Interpretation of Survey Results}

The existence of the self-potential anomalies associated with the fault become clear from the above-mentioned survey results.

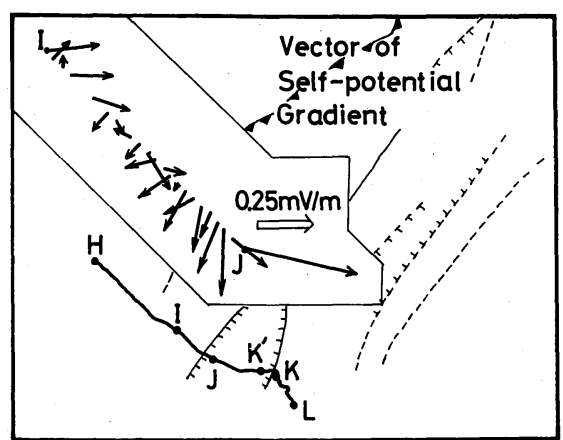

Fig. 8. Vectors of self-potential gradient along line I-J. Line I-J traverses Quanternary fault. Vector arrow indicates the direction of high potential. 

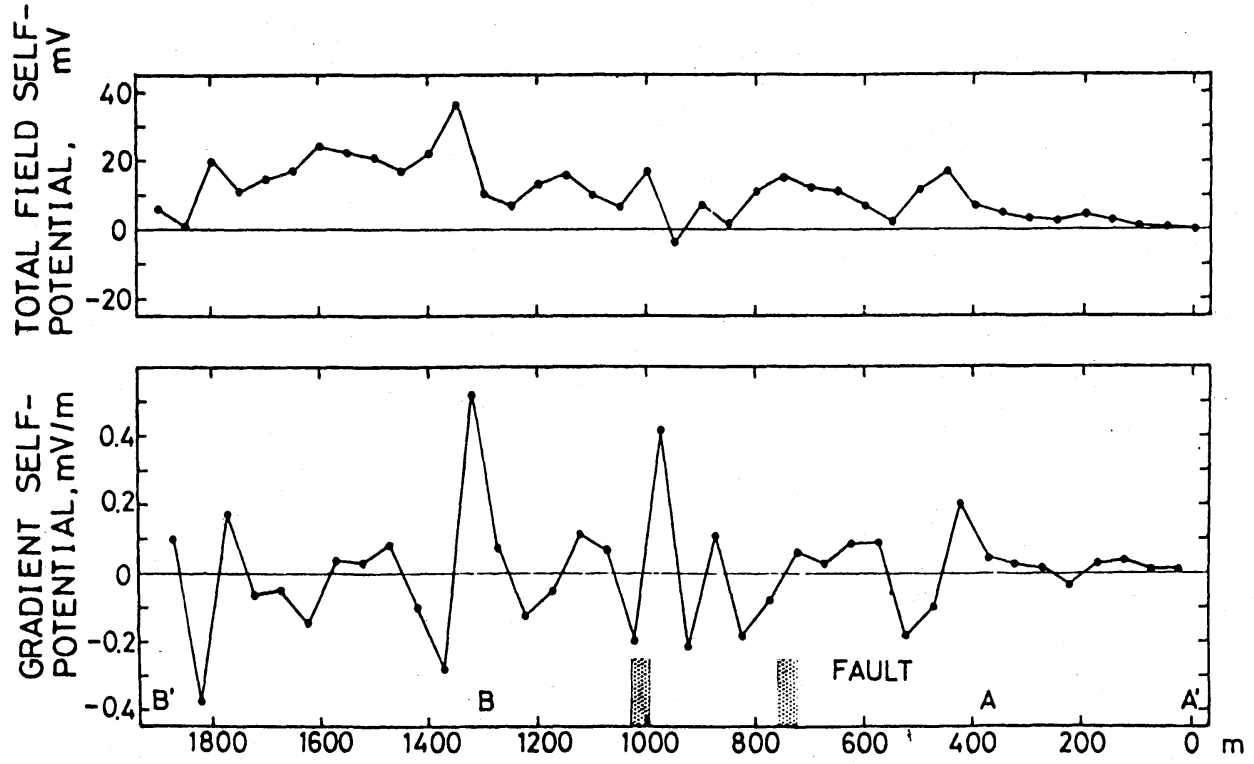

Fig. 9. Gradient and total field self-potential profile across two Quaternary faults, line B'-B-AA'.

Figure 10 shows the summary of the total field self-potential across the fault. The top of Fig. 10 is the northernmost profile of the total field self-potential, and the bottom is the southernmost profile. Figure 10 suggests the following facts:

(1) The self-potentials on the east side of the fault are about 20 to $50 \mathrm{mV}$ larger than those on the west side. The step-like jump of the self-potential distribution occurs within about $100 \sim 200 \mathrm{~m}$; i.e. the gradient of the self-potential near the fault is about 0.1 to $0.5 \mathrm{mV} / \mathrm{m}$.

(2) The positions of the step of the self-potential profiles across the fault deviate more east from the surface fault trace as the survey line goes down to the south.

What causes these stepped self-potential anomalies at the fault? In general, there are many possible causes for the self-potential anomalies. It is well known that the anomalies of the self-potential in ore deposit area may be explained by what is called "mineralized potential", which is due to the electrochemical polarization of graphite, sulfide, etc. (SATO and MoONEY, 1968). The positive anomalies in the geothermal area may be explained by the streaming potential due to hydrothermal convection in the ground (IsHIDO, 1981). Self-potential anomalies around a faulted half-space are suggested by FITTERMAN (1979a, 1979b) based on an electrokinetic theory. Electrokinetic phenomena, which are generated by the flow of the groundwater owing to the electric double layer formed at a solid-liquid interface, are proposed for self-potential and geomagnetic anomalies associated with earthquakes by MizUTANi et al. (1976) and FitTERMAN (1978, 


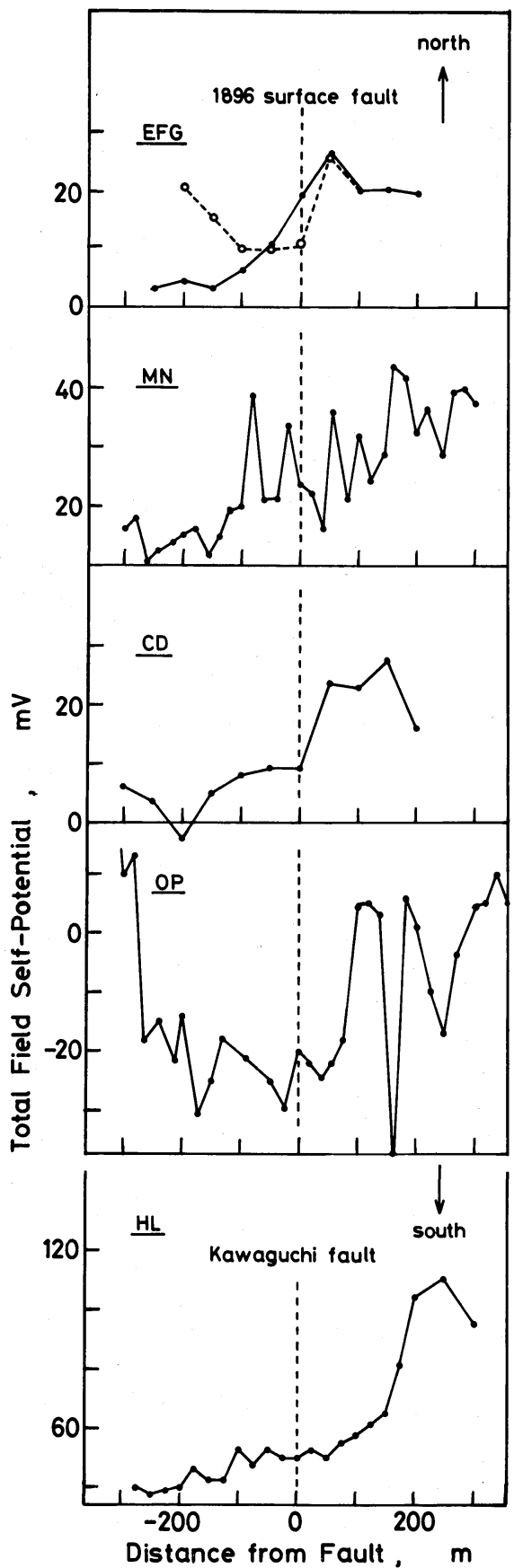

Fig. 10. Summary of total field self-potential profiles across fault lines. The top is the northernmost profile, and the bottom is the suthernmost profile. 
1979a, 1979b, 1981). NouRBEHECHT (1963) formulated the problem of selfpotential anomalies generated by the electrokinetic mechanism in inhomogeneous media and applied his results to the case of an underground nuclear explosion.

Older methods of interpretation were mostly based on polarized sphere or line dipole current sources. Although these techniques are useful, they provide little information about the nature of the sources. The electrokinetic approach provides information about the actual physical processes. We consider the electrokinetic mechanism as cause of observed self-potential anomalies because it is likely that there is fluid flowing out from the fault or across it. It is particularly so in this area because there are several hot springs around the fault zone.

According to MIZUTANI et al. (1976), the cross-coupled relations between the electric current flow and the fluid flow are described by the following two phenomenological equations,

$$
\begin{aligned}
& -i=L_{11} \operatorname{grad} E+L_{12} \operatorname{grad} P \\
& -j=L_{21} \operatorname{grad} E+L_{22} \operatorname{grad} P
\end{aligned}
$$

where $i$ is the electric current density, $j$ the fluid flux, $E$ the electric potential, $P$ the fluid pressure (above hydrostatic), and $L_{i j}$ the phenomenological coefficients. The first term on the right-hand side in Eq. (1) represents Ohm's law, and the second term in Eq. (2) represents Darcy's law. The term with $L_{12}$ and $L_{21}$ correspond to the electrokinetic effect, and $L_{12}=L_{21}$ according to Onsager's reciprocal relations. According to the nonequilibrium thermodynamics, the equation for the entropy production is given by

$$
\Lambda=-i \operatorname{grad} E-j \operatorname{grad} P \text {. }
$$

The steady states are also states of the minimum entropy production compatible with the external constrains. When grad $P=$ constant is imposed on the homogeneous system, the entropy production becomes

$$
\Lambda=-L_{11}(\operatorname{grad} E)^{2}-A \operatorname{grad} E-B
$$

where $A=2 L_{12} \operatorname{grad} P$ and $B=L_{22}(\operatorname{grad} P)^{2}$. From the condition of the minimum entropy production, the state is given by

$$
\begin{aligned}
(\partial \Lambda / \partial \operatorname{grad} E)_{\operatorname{grad} P} & =-2 L_{11} \operatorname{grad} E-2 L_{12} \operatorname{grad} P \\
& =2 i=0 .
\end{aligned}
$$

If the medium is homogeneous, the electric current density in the steady state is equal to zero, i.e., a magnetic field is not produced. In this condition the electric potential gradient is related to the fluid pressure gradient by 


$$
\begin{aligned}
\operatorname{grad} E & =-C \operatorname{grad} P \\
C & =L_{12} / L_{11}=(\varepsilon \zeta / \sigma \eta)
\end{aligned}
$$

where $C$ is the streaming potential coefficient, $\varepsilon$ the dielectric constant of the fluid, $\zeta$ the zeta potential, $\sigma$ the electric conductivity of the fluid, and $\eta$ the viscosity of the fluid. Equation (6) shows that the electric potential gradient is proportional to the fluid pressure gradient. Also, the general form of Eq. (6) is given by

$$
E=-C \cdot P+\text { constant }
$$

Equation (7) suggests that the electric potential on the surface is equal to a constant value because the fluid pressure (above hydrostatic) on the surface is equal to zero.

In order to apply the electrokinetic theory to the observed self-potentials, we should consider the electrokinetic phenomena in the inhomogeneous media, where there is the boundary separating regions of different streaming potential coefficients. From

$$
-i=L_{11}\left[\operatorname{grad} E+\left(L_{12} / L_{11}\right) \operatorname{grad} P\right]
$$

we can get

$$
-i=L_{11} \operatorname{grad} V
$$

where $V$ is defined as the sum of electric potential $E$ and the potential induced through the electrokinetic coupling

$$
V=E+\left(L_{12} / L_{11}\right) P=E+C \cdot P \text {. }
$$

The potential $V$ is called the "total electric potential". In the absence of current sources,

$$
\operatorname{div} i=0
$$

and for homogeneous regions the total electric potential satisfies Laplace's equation,

$$
\nabla^{2} V=0
$$

but its value on the boundary depends on $E, C$, and $P$. Using the boundary conditions for the continuity of the electric potential $\left(E_{1}=E_{2}\right)$, the pressure $\left(P_{1}=P_{2}\right)$, and the normal component of current flow $\left(j_{1} \cdot n=j_{2} \cdot n\right)$, we can write 
the boundary conditions for $V$;

$$
V_{1}-V_{2}=\left(C_{1}-C_{2}\right) P_{12}
$$

and

$$
\sigma_{1}\left(\partial V_{1} / \partial n\right)=\sigma_{2}\left(\partial V_{2} / \partial n\right)
$$

where subscripts 1 and 2 refer to the two media in contact, $P_{12}$ is the value of the pressure at the boundary, $\sigma$ the conductivity, $C$ the streaming potential coefficient, and $n$ the unit vector normal to the boundary. If the pressure on the surface is equal to zero, the potential $V$ is caused by sources distributed along the boundaries and the pressure $P$ enters only in the boundary condition (13) through its value at the boundary $P_{12}$. Next we consider the model, assuming $P(z=0)=0$.

As shown in Fig. 11, we now consider a faulted half-space with strike parallel to the $x$-axis as considered by FITTERMAN (1979a). The dip angle of the source is $\psi$. On the upper side of the contact the electric conductivity is $\sigma_{1}$ and the streaming potential coefficient $C_{1}$, while on the lower side of the contact the properties are $\sigma_{2}$ and $C_{2}$, respectively. The electrokinetic source is bounded by $-l / 2 \leqq x_{0} \leqq l / 2, \quad y_{1} \leqq y_{0} \leqq y_{2}$, and $a \leqq z_{0} \leqq b$ in which the source intensity $\left[S=\left(C_{1}-C_{2}\right) P\right]$ is constant. Outside of this region, the source has a value of zero. With these assumptions and the boundary condition of no current flow out of the half-space

$$
(\partial V / \partial z)_{z=0}=0
$$

the total electric potential is uniquely determined by Eq. (12) and the two boundary conditions (13) and (14). As we show in Appendix A, the solution is given by the following equation:

$$
\begin{aligned}
& V_{1 / 2}(x, y, 0) \\
& =\int_{-\infty}^{\infty} \mathrm{d} x_{0} \int_{0}^{\infty} \mathrm{d} z_{0} \frac{S\left(x_{0}, z_{0}\right) \cdot y \cdot \sin \psi}{\pi\left(1+\sigma_{1 / 2} / \sigma_{2 / 1}\right)\left[\left(x-x_{0}\right)^{2}+\left(y-z_{0} / \tan \psi\right)^{2}+z_{0}^{2}\right]^{3 / 2}} \\
& =\frac{S \cdot \sin \psi}{\pi\left(1+\sigma_{1 / 2} / \sigma_{2 / 1}\right)} \\
& \quad \times\left[-\arctan \left\{\frac{(b-y \cdot \sin \psi \cdot \cos \psi) \cdot(x-l / 2)}{y \cdot \sin \psi \sqrt{(b-y \cdot \sin \psi \cdot \cos \psi)^{2}+y^{2} \cdot \sin ^{4} \psi+(x-l / 2)^{2} \cdot \sin ^{2} \psi}}\right\}\right. \\
& \quad+\arctan \left\{\frac{(b-y \cdot \sin \psi \cdot \cos \psi) \cdot(x+l / 2)}{y \cdot \sin \psi \sqrt{(b-y \cdot \sin \psi \cdot \cos \psi)^{2}+y^{2} \cdot \sin ^{4} \psi+(x+l / 2)^{2} \cdot \sin ^{2} \psi}}\right\}
\end{aligned}
$$



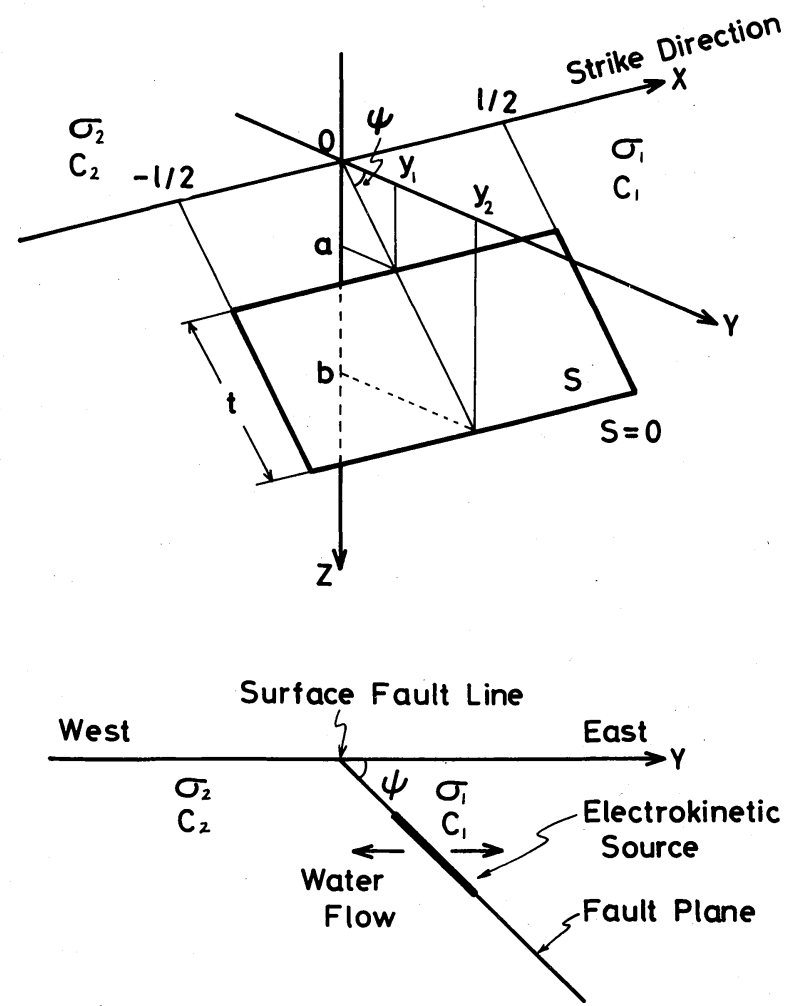

- Fault Model -

Fig. 11. Geometry of the electrokinetic source. Inside the region $y_{1} \leqq y_{0} \leqq y_{2},-l / 2 \leqq x_{0} \leqq l / 2, a \leqq z_{0} \leqq b$, the product of excess fluid pressure times the change in the streaming potential coefficient is constant $\left[S=\left(C_{1}-C_{2}\right) \cdot P\right]$. Over the rest of the source plane, $S=0$. The dip angle of the source is $\psi$. The lower figure is a cross section of the fault model.

$$
\begin{aligned}
& +\arctan \left\{\frac{(a-y \cdot \sin \psi \cdot \cos \psi) \cdot(x-l / 2)}{y \cdot \sin \psi \sqrt{(a-y \cdot \sin \psi \cdot \cos \psi)^{2}+y^{2} \cdot \sin ^{4} \psi+(x-l / 2)^{2} \cdot \sin ^{2} \psi}}\right\} \\
& \left.-\arctan \left\{\frac{(a-y \cdot \sin \psi \cdot \cos \psi) \cdot(x+l / 2)}{y \cdot \sin \psi \sqrt{(a-y \cdot \sin \psi \cdot \cos \psi)^{2}+y^{2} \cdot \sin ^{4} \psi+(x+l / 2)^{2} \cdot \sin ^{2} \psi}}\right\}\right] .
\end{aligned}
$$

The uppersubscripts are used for the upper side of the contact plane, and the lowersubscripts are used for the lower side. Equation (16) is equal to Eq. (33) in Fitterman's paper (FITTERMAN, 1979a) when the dip angle is $\pi / 2$.

The 1896 surface faults strike NS and dip east. The eastern side of the fault is upthrown. The typical length of the surface ruptures is about $5 \mathrm{~km}$ long. The electrical conductivities around the fault were determined using electromagnetic 
methods (Ono and Uchida, 1981; Sumitomo and Utada, 1981). The east side of the fault is dominated by the conductivity of 0.029 to $0.050 \mathrm{~S} / \mathrm{m}$ at depths deeper than $300 \mathrm{~m}$, whereas the west side shows the conductivity of 0.017 to $0.020 \mathrm{~S} / \mathrm{m}$ at the same depth. It is thought that the contact plane between two different layers along the fault plane is the electrokinetic source. Based on the above-mentioned facts, we calculate the self-potential distribution for the fault model using Eq. (16) with the source length of $l=5000 \mathrm{~m}$, the conductivity of the east side of the fault $\sigma_{1}=0.05 \mathrm{~S} / \mathrm{m}$, and the conductivity of the west side $\sigma_{2}=0.02 \mathrm{~S} / \mathrm{m}$. The depth of burial, $a$, the source width, $t$, and the electrokinetic intensity, $S$, were determined so as to fit the observed self-potentials. Figure 12 shows the theoretical self-potential profiles at $x=0$ on the surface for $l=5000$ $\mathrm{m}, t=250 \mathrm{~m}, a=10 \mathrm{~m}, S=0.1 \mathrm{~V}, \sigma_{1}=0.05 \mathrm{~S} / \mathrm{m}, \sigma_{2}=0.02 \mathrm{~S} / \mathrm{m}$, and three dip angles $\psi=30^{\circ}, 45^{\circ}, 90^{\circ}$, respectively. As shown in Fig. 12, the calculated selfpotential profiles across the fault are very similar to the observed self-potential profiles across the fault. As the dip angle increases from $30^{\circ}$ to $90^{\circ}$, the amplitude of the step-like variation increases, but the positions of the step do not change appreciably. The latter observation indicates that the surface self-potential profile is controlled by the physical state at a shallow depth. When the dip angle is $90^{\circ}$, the self-potential values decrease rather significantly to the west from the fault. Since this feature is not observed in the real data shown in Fig. 10, the dip angle of this fault must be much smaller than $90^{\circ}$. This is consistent with the geological studies by MATSUDA et al. (1980) who report that the dip angle of this fault plane is variable, ranging from almost vertical to less than $20^{\circ}$, and that the mean dip angle is about $45^{\circ}$. In the following we fit the

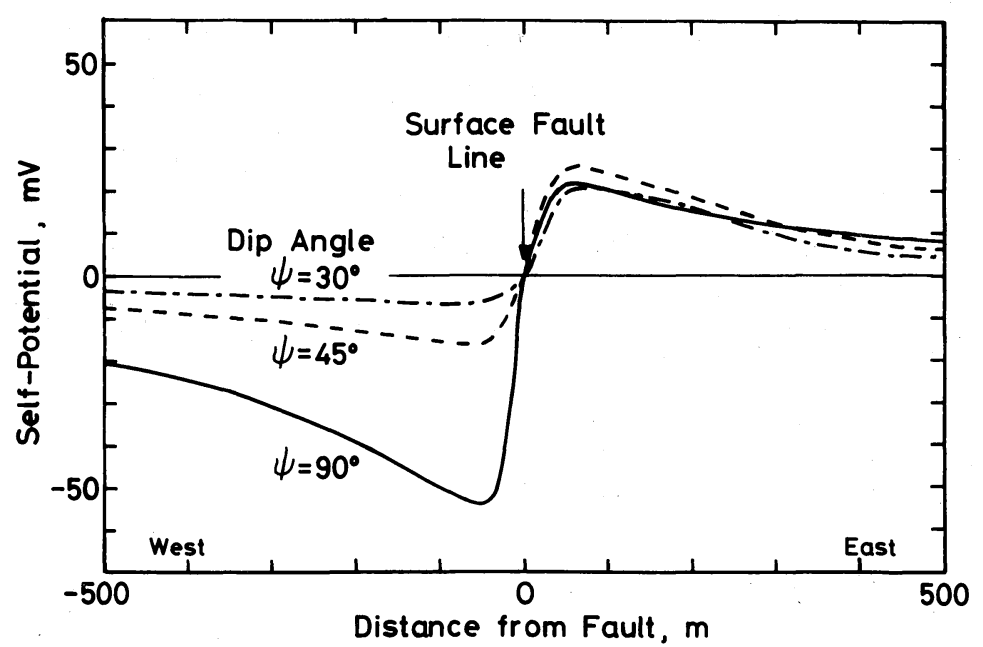

Fig. 12. Self-potential profile at $x=0$ on the surface for the fault model with $l=5000 \mathrm{~m}, t=250$ $\mathrm{m}, a=10 \mathrm{~m}, \sigma_{1}=0.05 \mathrm{~S} / \mathrm{m}, \sigma_{2}=0.02 \mathrm{~S} / \mathrm{m}$, and $S=0.1 \mathrm{~V}$, showing the effects of variations in the dip angle of the source. 
theoretical calculation with the observed self-potential distribution, assuming the dip angle $\psi=45^{\circ}$. We calculated the theoretical profiles of the self-potential distribution across the fault, using various values of $a, b$, and $S$. The $b$ value, which is the maximum depth of the source area, does not significantly effect the profile and so this parameter is not well determined by this calculation. We assume that the parameter $b$ is always larger than $a$, the minimum depth of the source area, by $t=250 \mathrm{~m}$. The parameter $a$ controls the shape of the profile. As the parameter $a$ becomes smaller, the step of the self-potential distribution is steeper. In order to fit the observed profile, we find the minimum depth of the source area, $a$, should be around $10 \sim 30 \mathrm{~m}$. Although the geological and/or geophysical meaning of the depth of the source area, $a$, is not clear at the present stage, it may correspond to the depth of the groundwater table in this area. KONISHI (1966) reported that the depth of the aquifer of the spring zone near the 1896 surface fault was around $10 \sim 32 \mathrm{~m}$. Since the source intensity $S$ is directly related to the amplitude of the self-potential variation, the parameter $S$ is rather uniquely determined from comparison of the observed amplitude of $20 \sim 50 \mathrm{mV}$ with the theoretical values. We obtained the source intensity $S$ to be $0.1 \sim 0.5$ V. The observation that the positions of the step of the self-potential profiles across the fault deviate more east from the surface fault trace as the survey line goes down to the south must be attributed to changes along the fault of the relative position of the source area with respect to the surface fault trace. Three possible models are considered, as shown in Fig. 13. As the position of the step of the self-potential profiles is controlled by the position of the shallowest part of the source, each model seems to explain the observed trend. But if we take the (a) model, the calculated step is more gentle in the southern profile than in the northern one. This is rather opposite to the observation, shown in Fig. 10. And the (b) model does not explain the observed trend on the position of the step of the self-potential profiles relative to the surface fault trace. Thus the (c) model is more likely to explain the observed trend. The above inference is consistent with the report by MATSUDA et al. (1980) where the dip angle varies from about $60^{\circ}$ at Ota fault to $45^{\circ} \sim 20^{\circ}$ at Senya fault and thick pleistocene fluvial deposits are distributed at Senya fault.

According to the experiment results of IsHIDo and MizuTANi (1981), the difference of the streaming potential coefficients of various minerals and rocks is in the range of 0.01 to $0.4 \mathrm{~V} / \mathrm{bar}$. Assuming that the difference of the streaming potential coefficients across the fault surface, $\Delta C=C_{1}-C_{2}$, is order of 0.1 $\mathrm{V} / \mathrm{bar}$, the fluid pressure (above hydrostatic) at the fault should be in the range of 1 to 5 bars higher than that around it. It is considered that the fluid ascends along the fault plane from the deeper part.

Figure 14 shows the distribution of the self-potential near the end of the fault, which is calculated by the same electrokinetic model as shown in Fig. 12. Calculated vectors of the self-potential gradient along I'-J' line and the observed ones along I-J survey line (duplicated from Fig. 8) are also compared in Fig. 14. As shown in Fig. 14, the theoretical pattern of the vectors is similar 


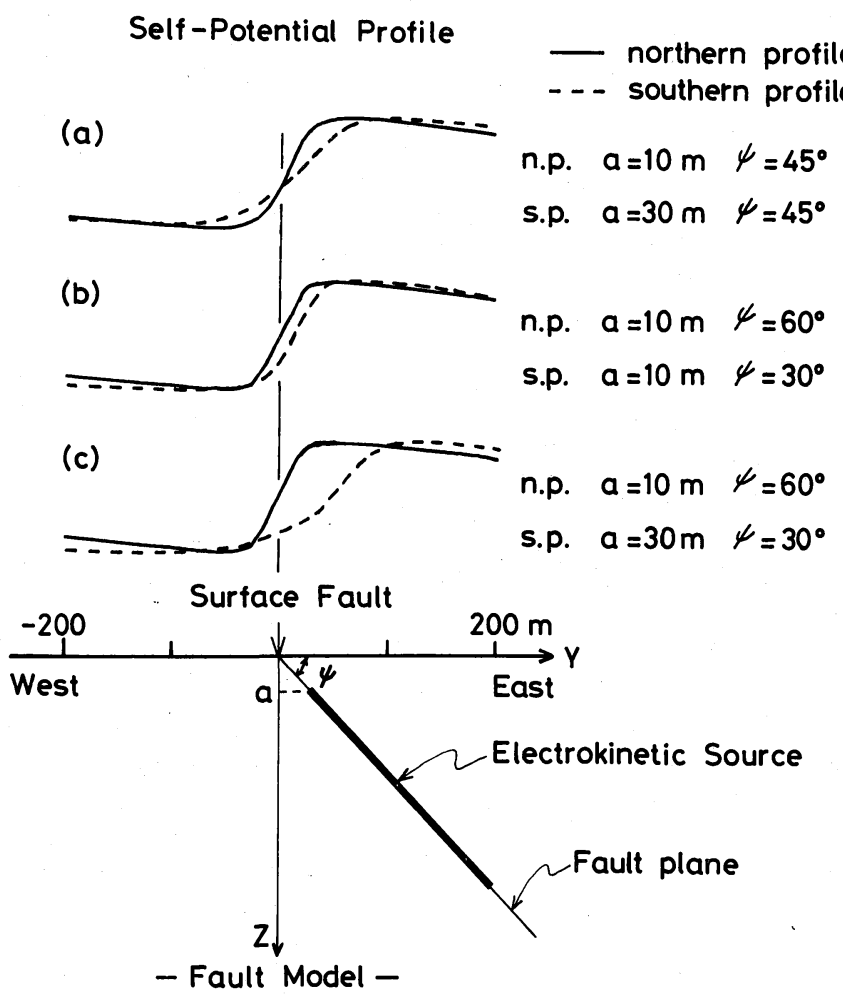

Fig. 13. Theoretical surface self-potential profile across the fault line. The solid line represents the northern profile in the survey area and the dashed line, the southern one. (a) Change depth; surface voltage $(x=0)$ for the electrokinetic source, showing the effects of variations for the source depth, $a$. (b) Change dip angle; surface voltage $(x=0)$ for the electrokinetic source, showing the effects of variations for the dip angle of the source, $\psi$. (c) Change depth and dip angle; surface voltage $(x=0)$ for the electrokinetic source, showing the effects of variations for the depth and dip angle. The profile is calculated for the source with parameters $l=5000 \mathrm{~m}, \sigma_{1}=0.05 \mathrm{~S} / \mathrm{m}, \sigma_{2}=0.02 \mathrm{~S} / \mathrm{m}$, and $t=250 \mathrm{~m}$ and normalized by the maximum amplitude.

to the observations except for the part near point I. Therefore, we conclude the variation in the direction of vectors of the self-potential gradient along I-J line may be explained as the edge effect of the source.

The electrokinetic source could produce not only the self-potential anomalies but also the geomagnetic anomalies. We can calculate the magnetic anomalies based on Fitterman's theory (FITTERMAN, 1981). As was suggested by FiTTERMAN (1981), we also use Edward's approximation (EDWARDS, 1974) to simplify the calculation. We calculate the magnetic field produced by current dipoles distributed on the source area (see Appendix B). Figure 15 shows the observed total intensity anomaly (MISHINA and YAMASHITA, 1981) and the calculated anomaly for the electrokinetic model with $l=5000 \mathrm{~m}, t=250 \mathrm{~m}, a=10 \mathrm{~m}, S=0.1 \mathrm{~V}$, 


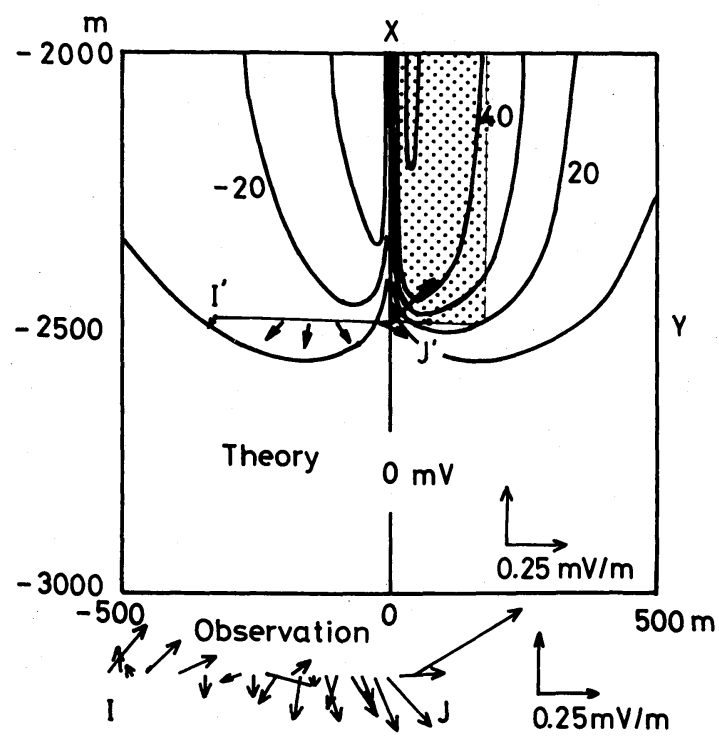

Fig. 14. Theortical self-potential distribution $(z=0)$ around the end of the source, theoretical pattern of the self-potential gradient, and the observed pattern of it. Theoretical pattern is calculated for the source with parameters $l=5000 \mathrm{~m}, t=250 \mathrm{~m}, a=10 \mathrm{~m}, \sigma_{1}=0.05 \mathrm{~S} / \mathrm{m}, \sigma_{2}=0.02 \mathrm{~S} / \mathrm{m}$, $S=0.1 \mathrm{~V}$, and $\psi=45^{\circ}$. A vector arrow indicates the direction of high potential. The dotted area is a part of the source.

$\sigma_{1}=0.05 \mathrm{~S} / \mathrm{m}, \sigma_{2}=0.02 \mathrm{~S} / \mathrm{m}$, and $\psi=45^{\circ}$. The calculated result is obtained using 1923 dipoles whose length $T$ is $0.7 \mathrm{~m}$. The current dipoles are positioned at every $7.8 \mathrm{~m}$ in the direction of the strike and every $83.3 \mathrm{~m}$ in the direction of the dip of the square source region. Lateral spacing density of the dipoles is important to obtain the surface magnetic anomaly reliably. Of course a higher density of the dipole spacing is more desirable, but the calculation time necessarily becomes longer. We find the present spacing of the dipole is saved enough to reproduce the magnetic field calculated with higher density spacing. As shown in Fig. 15, we find the magnetic field produced by the electrokinetic source is only $0.2 \mathrm{nT}$. This value is too small to explain the observed magnetic anomalies in the range of a few $\mathrm{nT}$ to several hundred $\mathrm{nT}$ at the fault. In order to explain the magnetic anomalies by the electrokinetic model, we must consider the very large source intensity and the very high conductive layer. The calculated results can be scaled to any other conductivities as follows

$$
B\left(\sigma_{1}^{\prime}, \sigma_{2}^{\prime}\right)=\frac{\sigma_{1}^{\prime} \sigma_{2}^{\prime}}{\sigma_{1}^{\prime}+\sigma_{2}^{\prime}} \cdot \frac{\sigma_{1}+\sigma_{2}}{\sigma_{1} \sigma_{2}} B\left(\sigma_{1}, \sigma_{2}\right)
$$

where $\sigma_{1}^{\prime}$ and $\sigma_{2}^{\prime}$ are the new conductivities. If the conductivities $\sigma_{1}^{\prime}, \sigma_{2}^{\prime}$ are $1 \mathrm{~S} / \mathrm{m}$, the magnetic anomaly of about $7 \mathrm{nT}$ is generated. But the electrical 


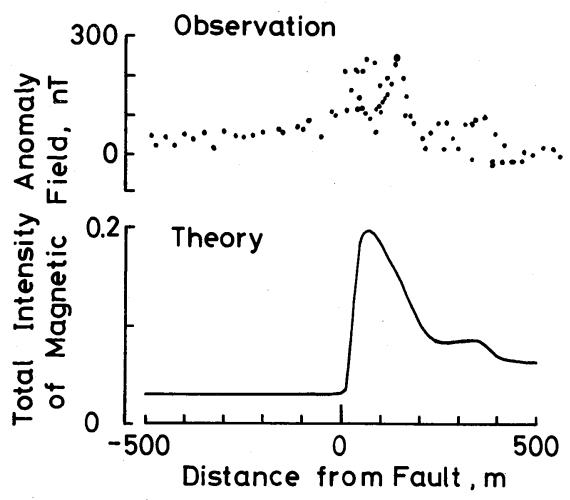

Fig. 15. Observed and theoretical anomaly of the total intensity of the geomagnetic field. Theoretical profile $(x=0)$ is calculated for the model with $l=5000 \mathrm{~m}, t=250 \mathrm{~m}, a=10 \mathrm{~m}, \sigma_{1}=0.05 \mathrm{~S} / \mathrm{m}$, $\sigma_{2}=0.02 \mathrm{~S} / \mathrm{m}, S=0.1 \mathrm{~V}$, and $\psi=45^{\circ}$, using 1923 current dipoles of which the length is 0.7 $\mathrm{m}$. The total intensity was observed along the survey line O-Q-P (MISHINA and YAMASHITA, 1981).

conductivity distribution in this area obtained by ONO and UCHIDA(1981) and Sumitomo and UtADA (1981) does not show such a high value anywhere. The large magnetic anomaly should have a different origin from that of the selfpotential anomaly. Magnetic anomalies in this area have the origin in the existence of highly magnetized materials intruded along the fault plane as pointed out by Mishina and YAMASHiTA (1981).

\section{Conclusions}

We surveyed the self-potentials around the 1896 surface faulting in order to investigate the fault activity and the geoelectric structure of it. The step-like self-potential profile with an amplitude of about 20 to $50 \mathrm{mV}$, was observed across the surface fault. These anomalies appear to be explained by the electrokinetic processes associated with the fluid flow presumably related to the fault activity. Comparison of the numerical calculation of the surface potential based on the electrokinetic effect with the observed ones indicates that the fluid pressure (above hydrostatic) at the fault is a few bars higher than that around the fault. Probably the high pressure water may originate in a deeper part, ascend along the fault plane, and appears as springs around the fault area. However, it may be necessary to increase the accuracy and density of the self-potential measurements so as to conclude uniquely the observed self-potential anomaly as the electrokinetic origin. On the other hand, the observed anomalous high values $(\sim 300 \mathrm{nT})$ of the magnetic total field around the fault zone were not explained by the electrokinetic current. The magnetic anomalies may be attributed to the existence of highly magnetized material near the fault zone, which is due to the integrated results related to the fault activity. 
It is very likely that accurate measurement of the self-potential provides a useful tool for mapping the active fault and that geophysical insight on the fault may be obtained from the self-potential distribution.

It is a pleasure to acknowledge many helpful suggestions and assistance of Professor K. Noritomi, Mining College, Akita University, Professor T. Yukutake, Earthquake Research Institute, University of Tokyo, and the members of Electromagnetic Research Group for the Active Fault (Japan).

Appendix A: The Potential Caused by an Inclined Electrokinetic Source.

Although FitTERMAN (1979a) considered a vertical electrokinetic source, we consider an inclined electrokinetic source. The electric field and the magnetic field caused by the electrokinetic source are similar to those caused by the current dipole (FITTERMAN, 1979a, 1981). We consider an inclined current dipole at first. Figure 16 shows the current dipole model for analysis. The potential $(z=0)$ caused by the inclined dipole buried in a homogeneous half-space with the electrical conductivity $\sigma$ is given by the following equation (KIYONO, 1955):

$$
\begin{aligned}
V\left(x, y, 0 ; 0, y_{0}, z_{0}\right) & =\frac{M}{2 \pi \sigma} \cdot \frac{z_{0}^{2}-\left(z_{0} \cdot \tan \psi\right) \cdot\left(y_{0}-y\right)}{\sqrt{z_{0}^{2}+\left(z_{0} \cdot \tan \psi\right)^{2}}\left[x^{2}+\left(y-y_{0}\right)^{2}+z_{0}^{2}\right]^{3 / 2}} \\
& =\frac{M}{2 \pi \sigma} \cdot \frac{z_{0} \cdot \cos \psi-\left(y_{0}-y\right) \cdot \sin \psi}{\left[x^{2}+\left(y-y_{0}\right)^{2}+z_{0}^{2}\right]^{3 / 2}} \\
& =\frac{M}{2 \pi \sigma} \cdot \frac{y \cdot \sin \psi}{\left[x^{2}+\left(y-z_{0} / \tan \psi\right)^{2}+z_{0}^{2}\right]^{3 / 2}}
\end{aligned}
$$

where $M$ is the moment of the current dipole, and the inclined current dipole is located at the point $\left(0, y_{0}, z_{0}\right)$. Equation (A.1) derives from the following equation:

$$
\begin{aligned}
V\left(x, y, z ; 0, y_{0}, z_{0}\right)= & \frac{M \cdot \sin \psi}{4 \pi \sigma}\left\{\frac{y-y_{0}}{\left[x^{2}+\left(y-y_{0}\right)^{2}+\left(z-z_{0}\right)^{2}\right]^{3 / 2}}\right. \\
& \left.+\frac{y-y_{0}}{\left[x^{2}+\left(y-y_{0}\right)^{2}+\left(z+z_{0}\right)^{2}\right]^{3 / 2}}\right\} \\
& +\frac{M \cdot \cos \psi}{4 \pi \sigma}\left\{-\frac{z-z_{0}}{\left[x^{2}+\left(y-y_{0}\right)^{2}+\left(z-z_{0}\right)^{2}\right]^{3 / 2}}\right. \\
& \left.+\frac{z+z_{0}}{\left[x^{2}+\left(y-y_{0}\right)^{2}+\left(z+z_{0}\right)^{2}\right]^{3 / 2}}\right\} .
\end{aligned}
$$


This equation represents the potential at the point $(x, y, z)$ which is caused by the inclined current dipole located at the point $\left(0, y_{0}, z_{0}\right)$. The first term on the right-hand side in Eq. (A.2) represents the potential caused by the $y$-component of the inclined current dipole, and the second term represents the potential caused by the $z$-component of the inclined current dipole. The first term on the righthand side in Eq. (A.2) is equivalent to Eq. (22) in Fitterman's paper (FITTERMAN, 1979a). On referring to Eq. (22) in Fitterman's paper (FITTERMAN, 1979a), we assume the following equation for the faulted half-space shown in Fig. 11.

$$
\begin{aligned}
& V_{1 / 2}\left(x, y, z ; x_{0}, y_{0}, z_{0}\right) \\
&=\frac{S\left(x_{0}, y_{0}, z_{0}\right) \cdot \sin \psi}{2 \pi\left(1+\sigma_{1 / 2} / \sigma_{2 / 1}\right)}\left\{\frac{y-y_{0}}{\left[\left(x-x_{0}\right)^{2}+\left(y-y_{0}\right)^{2}+\left(z-z_{0}\right)^{2}\right]^{3 / 2}}\right. \\
&\left.\quad+\frac{y-y_{0}}{\left[\left(x-x_{0}\right)^{2}+\left(y-y_{0}\right)^{2}+\left(z+z_{0}\right)^{2}\right]^{3 / 2}}\right\} \\
& \quad+\frac{S\left(x_{0}, y_{0}, z_{0}\right) \cdot \cos \psi}{2 \pi\left(1+\sigma_{1 / 2} / \sigma_{2 / 1}\right)}\left\{-\frac{z-z_{0}}{\left[\left(x-x_{0}\right)^{2}+\left(y-y_{0}\right)^{2}+\left(z-z_{0}\right)^{2}\right]^{3 / 2}}\right. \\
&\left.+\frac{z+z_{0}}{\left[\left(x-x_{0}\right)^{2}+\left(y-y_{0}\right)^{2}+\left(z+z_{0}\right)^{2}\right]^{3 / 2}}\right\} .
\end{aligned}
$$

Equation (A.3) is a solution of Laplace's equation, and satisfies the boundary conditions of Eqs. (13), (14), and (15). Therefore, we can obtain the Green's function for our model from Eq. (A.3). We are concerned with surface measurements $(z=0)$, so the Green's function reduces to

$G_{1 / 2}\left(x, y, 0 ; x_{0}, y_{0}, z_{0}\right)$

$$
\begin{aligned}
& =\frac{1}{\pi\left(1+\sigma_{1 / 2} / \sigma_{2 / 1}\right)} \frac{\sin \psi \cdot y}{\left[\left(x-x_{0}\right)^{2}+\left(y-y_{0}\right)^{2}+z_{0}^{2}\right]^{3 / 2}} \\
& =\frac{1}{\pi\left(1+\sigma_{1 / 2} / \sigma_{2 / 1}\right)} \frac{\sin \psi \cdot y}{\left[\left(x-x_{0}\right)^{2}+\left(y-z_{0} / \tan \psi\right)^{2}+z_{0}^{2}\right]^{3 / 2}} \\
& =G_{1 / 2}\left(x, \mathrm{y}, 0 ; x_{0}, \mathrm{z}_{0}\right) .
\end{aligned}
$$

The solution for our model is given by the following equation:

$$
\begin{aligned}
V_{1 / 2}(x, y, 0) & =\int_{-\infty}^{\infty} \mathrm{d} x_{0} \int_{0}^{\infty} \mathrm{d} z_{0} \cdot G_{1 / 2}\left(x, y, 0 ; x_{0}, z_{0}\right) \cdot S\left(x_{0}, z_{0}\right) \\
& =\frac{S \cdot \sin \psi}{\pi\left(1+\sigma_{1 / 2} / \sigma_{2 / 1}\right)} \int_{-l / 2}^{l / 2} \dot{\mathrm{d}} x_{0} \int_{a}^{b} \mathrm{~d} z_{0} \frac{y}{\left[\left(x-x_{0}\right)^{2}+\left(y-z_{0} / \tan \psi\right)^{2}+z_{0}^{2}\right]^{3 / 2}}
\end{aligned}
$$




$$
S\left(x_{0}, z_{0}\right)=\left\{\begin{array}{l}
S,-l / 2 \leqq x_{0} \leqq l / 2, a \leqq z_{0} \leqq b \\
0, \text { elsewhere }
\end{array}\right.
$$

Using the formula (MORIGUCHI et al., 1979, pp. 111)

$$
\int \frac{\mathrm{d} x}{\left[x^{2}+C\right]^{3 / 2}}=\frac{x}{C\left[x^{2}+C\right]^{1 / 2}},
$$

the integrated form of Eq. (A.5) with respect to $x_{0}$ is as follows: $V_{1 / 2}(x, y, 0)$

$$
\begin{aligned}
= & \frac{S \cdot \sin \psi}{\pi\left(1+\sigma_{1 / 2} / \sigma_{2 / 1}\right)} \int_{a}^{b} \mathrm{~d} z_{0} \\
& \times y\left[-\frac{x-l / 2}{\left[\left(y-z_{0} / \tan \psi\right)^{2}+z_{0}^{2}\right]\left[(x-l / 2)^{2}+\left(y-z_{0} / \tan \psi\right)^{2}+z_{0}^{2}\right]^{1 / 2}}\right. \\
& \left.+\frac{x+l / 2}{\left[\left(y-z_{0} / \tan \psi\right)^{2}+z_{0}^{2}\right]\left[(x+l / 2)^{2}+\left(y-z_{0} / \tan \psi\right)^{2}+z_{0}^{2}\right]^{1 / 2}}\right]
\end{aligned}
$$

Next, we arrange Eq. (A.6) with respect to $z_{0}$ in order to obtain the integration easily.

$$
\begin{aligned}
V_{1 / 2}(x, & y, 0)=\frac{S \cdot \sin ^{4} \psi}{\pi\left(1+\sigma_{1 / 2} / \sigma_{2 / 1}\right)} \int_{a}^{b} \mathrm{~d} z_{0} \\
& \times y\left[\frac{-1}{\left[\left(z_{0}-y \cdot \sin \psi \cdot \cos \psi\right)^{2}+y^{2} \cdot \sin ^{4} \psi\right]}\right. \\
& \times \frac{x-l / 2}{\left[\left(z^{0}-y \cdot \sin \psi \cdot \cos \psi\right)^{2}+y^{2} \cdot \sin ^{4} \psi+(x-l / 2)^{2} \cdot \sin ^{2} \psi\right]^{1 / 2}} . \\
& +\frac{1}{\left[\left(z_{0}-y \cdot \sin \psi \cdot \cos \psi\right)^{2}+y^{2} \cdot \sin ^{4} \psi\right]} \\
& \left.\times \frac{x+l / 2}{\left[\left(z^{0}-y \cdot \sin \psi \cdot \cos \psi\right)^{2}+y^{2} \cdot \sin ^{4} \psi+(x+l / 2)^{2} \cdot \sin ^{2} \psi\right]^{1 / 2}}\right]
\end{aligned}
$$

Using the formula (MORIGUCHI et al., 1979, pp. 130)

$$
\begin{gathered}
\int \frac{\mathrm{d} x}{\left[x^{2}+p^{2}\right]\left[a x^{2}+c\right]^{1 / 2}}=\frac{1}{p\left[c-a p^{2}\right]^{1 / 2}} \arctan \left(\frac{x\left[c-a p^{2}\right]^{1 / 2}}{p\left[a x^{2}+c\right]^{1 / 2}}\right) \\
c>a p^{2},
\end{gathered}
$$


the integration of Eq. (A.7) results in

$$
\begin{aligned}
& V_{1 / 2}(x, y, 0) \\
& =\frac{S \cdot \sin \psi}{\pi\left(1+\sigma_{1 / 2} / \sigma_{2 / 1}\right)} \\
& \times\left[-\arctan \left\{\frac{(b-y \cdot \sin \psi \cdot \cos \psi) \cdot(x-l / 2)}{y \cdot \sin \psi \sqrt{(b-y \cdot \sin \psi \cdot \cos \psi)^{2}+y^{2} \cdot \sin ^{4} \psi+(x-l / 2)^{2} \cdot \sin ^{2} \psi}}\right\}\right. \\
& +\arctan \left\{\frac{(b-y \cdot \sin \psi \cdot \cos \psi) \cdot(x+l / 2)}{y \cdot \sin \psi \sqrt{(b-y \cdot \sin \psi \cdot \cos \psi)^{2}+y^{2} \cdot \sin ^{4} \psi+(x+l / 2)^{2} \cdot \sin ^{2} \psi}}\right\} \\
& +\arctan \left\{\frac{(a-y \cdot \sin \psi \cdot \cos \psi) \cdot(x-l / 2)}{y \cdot \sin \psi \sqrt{(a-y \cdot \sin \psi \cdot \cos \psi)^{2}+y^{2} \cdot \sin ^{4} \psi+(x-l / 2)^{2} \cdot \sin ^{2} \psi}}\right\} \\
& \left.-\arctan \left\{\frac{(a-y \cdot \sin \psi \cdot \cos \psi) \cdot(x+l / 2)}{y \cdot \sin \psi \sqrt{(a-y \cdot \sin \psi \cdot \cos \psi)^{2}+y^{2} \cdot \sin ^{4} \psi+(x+l / 2)^{2} \cdot \sin ^{2} \psi}}\right\}\right] \text {. }
\end{aligned}
$$

Appendix B: The Calculation of the Magnetic Field Caused by an Inclined Electrokinetic Source.

We calculate the magnetic field caused by an inclined electrokinetic source using Edward's approximation (EDWARDS, 1974). EDWARDS (1974) calculated the magnetic field produced by a current dipole buried in a half-space. While the mechanism producing the current flow in the case considered by EDWARDS (1974) is different from that in Fitterman's case (FITTERMAN, 1981), the resulting magnetic fields are similar. The magnetic field sources in Fitterman's theory (FITTERMAN, 1981) correspond to the magnetic field produced by the return current external to the dipole and the current inside the dipole. We calculate the magnetic field produced by the inclined current dipole in Fig. 16. According to Edwards' theory (EDWARDS, 1974), three components of the magnetic field at the point $\mathrm{P}$ in Fig. 16 due to the inclined current dipole are given by the following equations:

$$
\begin{aligned}
B x & =B \cdot \cos \phi+\frac{\mu I}{2 \pi}\left[\left(1-\sin \xi_{2}\right) \cdot\left(\cos \eta_{2} / r_{2}\right)-\left(1-\sin \xi_{1}\right) \cdot\left(\cos \eta_{1} / r_{1}\right)\right] \\
B y & =B \cdot \sin \phi \cdot \cos \psi+\frac{\mu I}{2 \pi}\left[\left(1-\sin \xi_{2}\right) \cdot\left(\sin \eta_{2} / r_{2}\right)-\left(1-\sin \xi_{1}\right) \cdot\left(\sin \xi_{1} / r_{1}\right)\right] \\
B z & =B \cdot \sin \phi \cdot \sin \psi \\
B & =-\frac{\mu I}{2 \pi R}\left(\cos \theta_{2}-\cos \theta_{1}\right)=-\frac{\mu I \cdot\left(\cos \theta_{2}-\cos \theta_{1}\right)}{2 \pi \sqrt{\left(x-x_{0}\right)^{2}+\left(z_{0} / \sin \psi-y \cdot \cos \psi\right)^{2}}}
\end{aligned}
$$




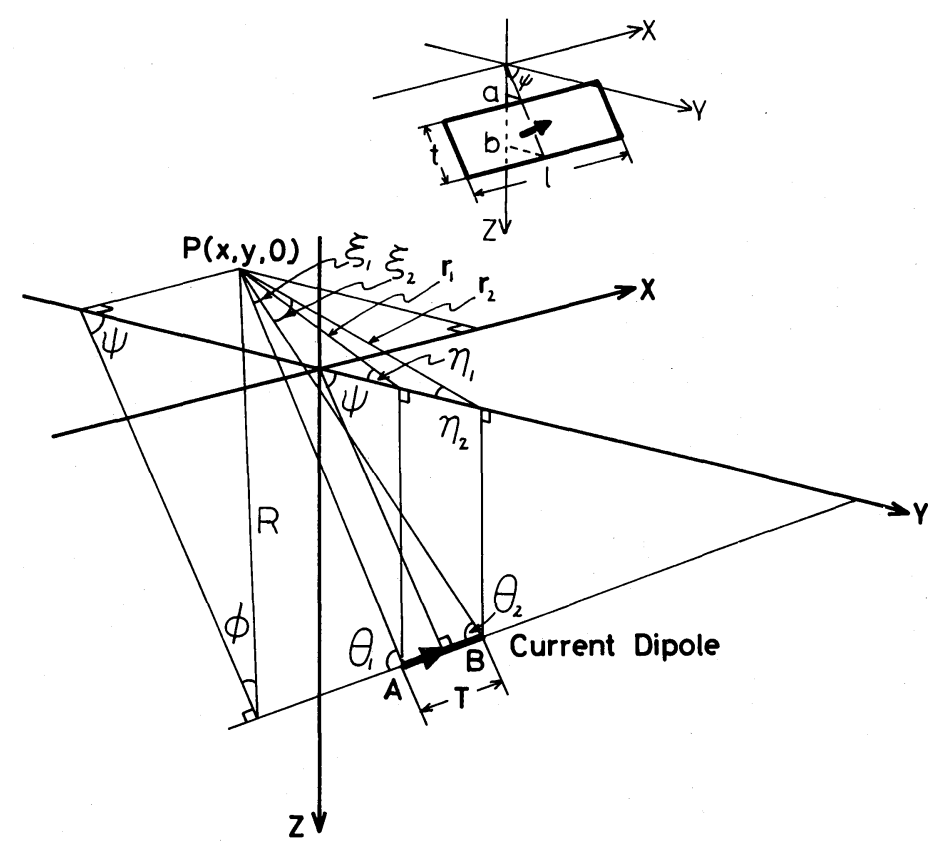

Fig. 16 Geometry of the current dipole in the source. A current flows from the earth into a current sink A, along a straight, insulated wire to a current source B and then from B into the earth.

where $I$ is the current intensity, $B$ the magnetic field due to the current inside the dipole, and $\mu$ the magnetic permeability of the medium. The current intensity is given by

$$
I=\frac{\sigma_{1} \sigma_{2}}{\sigma_{1}+\sigma_{2}} \cdot \frac{S}{T}
$$

where $T$ is the dipole length. We calculate the theoretical anomaly shown in Fig. 15 using Eq. (B.1).

We can demonstrate simply that the magnetic fields of Fitterman's model is equal to those of Edwards' model. For example, Equation (26) in Fitterman's paper (FITTERMAN, 1981) is given by integrating Eq. (6) in Edwards' paper (EDWARDS, 1974) over the source area with the dipole length $T \rightarrow 0$, and $\psi=\pi / 2$.

$$
\begin{aligned}
B x(x, y, 0) & =\int_{-l / 2}^{l / 2} \mathrm{~d} x_{0} \int_{a}^{b} \mathrm{~d} z_{0}\left[\lim _{T \rightarrow 0}-\frac{\sigma_{1} \sigma_{2} \mu S}{2 \pi\left(\sigma_{1}+\sigma_{2}\right) \cdot T \cdot R}\left(\cos \theta_{2}-\cos \theta_{1}\right) \cdot \cos \phi\right] \\
& =\int_{-l / 2}^{l / 2} \mathrm{~d} x_{0} \int_{a}^{b} \mathrm{~d} z_{0}\left[-\frac{\sigma_{1} \sigma_{2} \mu S z_{0}}{2 \pi\left(\sigma_{1}+\sigma_{2}\right)\left[\left(x-x_{0}\right)^{2}+z_{0}^{2}\right]}\right.
\end{aligned}
$$




$$
\begin{aligned}
& \left.\times\left(\frac{1}{\sqrt{\left(x-x_{0}\right)^{2}+y^{2}+z_{0}^{2}}}-\frac{y^{2}}{\sqrt{\left(x-x_{0}\right)^{2}+y^{2}+z_{0}^{2}}}\right)\right] \\
= & \frac{\sigma_{1} \sigma_{2} \mu S}{2 \pi\left(\sigma_{1}+\sigma_{2}\right)} \ln \left(\frac{\left[\left\{(x-l / 2)^{2}+y^{2}+a^{2}\right\}^{1 / 2}+(x-l / 2)\right]}{\left[\left\{(x+l / 2)^{2}+y^{2}+a^{2}\right\}^{1 / 2}+(x+l / 2)\right]}\right. \\
& \times \frac{\left[\left\{(x+l / 2)^{2}+y^{2}+b^{2}\right\}^{1 / 2}+(x+l / 2)\right]}{\left[\left\{(x-l / 2)^{2}+y^{2}+b^{2}\right\}^{1 / 2}+(x-l / 2)\right]} .
\end{aligned}
$$

\section{REFERENCES}

CORWIN, R. F. and H. F. MORRISON, Self-potential variations preceding earthquakes in central California, Geophys. Res. Lett., 4, 171-174, 1977.

EDWARDS, R. N. The magnetometric resistivity method and its application to the mapping of a fault, Can. J. Earth Sci., 11, 1136-1156, 1974.

ELECTROMAGNETIC RESEARCH GROUP FOR THE ACTIVE FAULT, Low electric resistivity along an active fault, the Yamasaki fault, J. Geomag. Geoelectr., 34, 103-127, 1982.

FITTERMAN, D. V., Electrokinetic and magnetic anomalies associated with dilatant regions in a layered earth, J. Geophys. Res., 83, 5923-5928, 1978.

FITTERMAN, D. V., Calculations of self-potential anomalies near vertical contacts, Geophysics, 44, 195-205, 1979a.

FITTERMAN, D. V., Theory of electrokinetic-magnetic anomalies in a faulted half-space, J. Geophys. Res., 84, 6031-6040, 1979b.

FITTERMAN, D. V., Corrrection to "Theory of electrokinetic-magnetic anomalies in a faulted halfspace”, J. Geophys. Res., 86, 9585-9588, 1981.

ISHIDO, T., Streaming potential associated with hydrothermal convection in the crust: a possible mechanism of self-potential anomalies in geothermal areas, J. Geotherm. Res. Soc. Japan, 3, 87-100, 1981 (in Japanese).

ISHIDO, T. and H. MIZUTANI, Experimental and theoretical basis of electrokinetic phenomena in rock-water systems and its application to geophysics, J. Geophys. Res., 86, 1763-1775, 1981.

KIYONO, T., Denkitanko-gaku 3, pp. 8-11, Kyoto University, Kyoto 1955 (in Japanese).

KONISHI, T., Hydrogeological study of the Yokote basin, Akita Prefecture, Rept. Geol. Surv. Japan, 216, 1-34, 1966 (in Japanese).

MAtSUdA, T., H. YAmAZAKI, T. NAKATA, and T. ImAIZUMI, The surface faults associated with the Rikuu earthquake of 1896, Bull. Earth Res. Inst., University of Tokyo, 55, 795-849, 1980 (in Japanese).

MishinA, M. and S. YamashitA, Magnetic anomaly due to the fault, in Study on Fault Activity Using Geoelectric and Geomagnetic Methods, Report of Scientific Research, Natural Disaster Science, A-56-2, edited by K. Noritomi, pp. 84-90, 1981 (in Japanese).

MizUTANI, H., T. ISHIDO, T. YOKOKURA, and S. OHNISHI, Electrokinetic phenomena associated with earthquakes, Geophys. Res. Lett., 3, 365-368, 1976.

Moriguchi, S., K. UdAGAWA, and S. HitotSUMATSU, Sugaku-koshiki 1, 318 pp., Iwanami, Tokyo, 1979 (in Japanese).

Noritomi, K. (organizer), Study on Fault Activity Using Geoelectric and Geomagnetic Methods, Report of Scientific Research, Natural Disaster Science, A-56-2, 107 pp., 1981 (in Japanese).

NOURBEHECHT, B., Irreversible thermodynamic effects in inhomogeneous media and their application in certain geoelectric problems, Ph. D. Thesis, Mass Inst. of Technol., Cambridge, Mass., 1963.

ONO, Y. and T. UCHIDA, Electrical resistivity structure near Senya fault, in Study on Fault Activity Using Geoelectric and Geomagnetic Methods, Report of Scientific Research, Natural Disaster Science, A-56-2, edited by K. Noritomi, pp. 58-63, 1981 (in Japanese). 
SATo, M. and H. M. Moony, The electrochemical mechanism of sulfide self-potentials, Geophysics, 25, 226-249, 1968.

SMith, B. E. and M. J. S. Johnston, A tectonomagnetic effect observed before a magnitude 5.2 earthquake near Hollister, California, J. Geophys. Res., 81, 3556-3560, 1976.

Sumitomo, N. and H. UTADA, Electrical resistivity structure determined by ELF-MT method, in Study on Fault Activity Using Geoelectric and Geomagnetic Methods, Report of Scientific Research, Natural Disaster Science, A-56-2, edited by K. Noritomi, pp. 64-67, 1981 (in Japanese).

YAMAZAKI, Y., Tectonoelectricity, Geophys. Surv., 3, 123-142, 1977. 